\title{
Research on the Effect of Peer Feedback Training in English Writing Teaching-A Case Study of Students in Business English Major
}

\author{
Jialiang Chen ${ }^{1}$ \\ ${ }^{1}$ School of English for International Business, Guangdong University of Foreign Studies, Guangzhou, China \\ Correspondence: Jialiang Chen, School of English for International Business, Guangdong University of Foreign \\ Studies, Guangzhou 510420, Guangdong, China.
}

Received: April 16, 2021

doi: 10.5539/elt.v14n6p12

\begin{abstract}
Based on peer feedback, this paper further explores the application of peer feedback training to English writing teaching in China. From the theoretical perspective, compared with teacher feedback, peer feedback is beneficial to motivate students to take the initiative in learning, practice the student-centered concept, and promote cooperative learning among students. Peer feedback training, namely peer feedback under teacher intervention in this paper, combines the advantages of teacher feedback and peer feedback, which can not only be accepted by learners but also achieve significant pragmatic effects. From a practical point of view, peer feedback training can be applied to teach large groups of students, thus reducing the pressure and burden of teachers and improving the quality of peer feedback. The results also show that peer feedback training mainly works during the training stage rather than the modification stage. It is crucial to pay attention to the mechanism of peer feedback training and apply it to practice to promote the quality of English writing teaching.
\end{abstract}

Keywords: English writing teaching, peer feedback, peer feedback training, case study

\section{Introduction}

Feedback is an essential part of the teaching process that helps learners to correct mistakes. First, it provides motivation and guidance for the writer to revise the composition until it is finished. Second, it strengthens the concept of audience and helps the author to change from a 'writer-based' perspective to a 'reader-based' one, so as to achieve the purpose of expressing meaning through writing. The effect of writing feedback can improve learner' writing skills and reflect the effectiveness of teachers' guidance involved (eg. Schunn et al., 2016).

Teacher feedback is dominant in English as a Foreign Language (EFL) writing teaching. For teachers, however, providing feedback for students is "a tedious and unrewarding job" (Hyland, 1990: 279). Large classes in China impose a heavy workload for teachers to correct students' writing, and no matter how carefully essays are corrected, the same mistakes continue to occur repeatedly. Consequently, the traditional method of teacher feedback has been questioned due to its poor effect, whereas the feasibility of peer feedback has been revealed in the research. Dheram (1995) believes that peer feedback can be used to improve students' initiative in writing. It should also be noted that any teaching method has its advantages and limitations, which means taking no account of the reality will only lead to passive teaching without much practical effect.

Peer feedback has risen to be another major feedback method apart from teacher feedback in English as a Second Language (ESL) writing classes. Theoretically deriving from the teaching theory of process writing and cooperative learning, especially Vygotsky's "Zone of Proximal Development" and "interaction theory of second language acquisition" (Liu \& Hansen, 2002), peer feedback has become an increasingly influential form of feedback in ESL writing teaching. Peer feedback is a writing teaching activity in which learners exchange their essays and propose suggestions for revision (Mangelsdorf, 1992) and it is also referred to as peer review, peer response, peer critiquing, peer evaluation, and peer editing, etc. Studies have shown that peer feedback can encourage learners to take an active part in writing (Mendonca \& Johnson, 1994), enhance students' willingness for revision, and create greater opportunities for learners to interact, negotiate and cooperate (Zhu, 1995), which are essential factors to improve learners' initiative (Lee, 1998).

Academic research has paid an increasing amount of attention to peer feedback in writing teaching, and effective ways to improve its quality have therefore been emphasized. Recent studies on English writing teaching have 
focused on peer feedback training, aiming to improve the quality of peer feedback dynamically and flexibly (e.g., Loretto et al., 2016; Min, 2016). This paper mainly refers to the research of peer feedback in writing teaching and explores the effect of peer feedback training in college English writing teaching after analyzing and discussing its effectiveness. Since little research has touched on peer feedback training as feedback under teacher intervention, the present study will try to explore the effect of peer feedback under teacher intervention on students' writing. Before the experiment, the author gives the following two hypotheses based on literature and previous studies: a) peer feedback under teacher intervention (i.e. peer feedback training) has a better effect than ordinary peer feedback; $b$ ) the effectiveness of peer feedback under teacher intervention is mainly reflected in the modification stage.

\section{Literature Review}

\subsection{Teacher Feedback \& Peer Feedback}

\subsubsection{Background of Peer Feedback}

As a writing teaching method, peer feedback refers to the teaching activity where students provide feedback for each other in a written or oral form through cooperation in the teaching process, so as to improve the quality of writing (Liu \& Hansen, 2002: 1). Peer feedback is used in writing teaching, which aims to improve and develop students' writing ability through their interaction and influence. This method is widely used in both ESL and EFL writing teaching. Research shows that peer feedback in writing teaching has gradually emerged and developed after the 1980s (cf. Brannon \& Knoblauch, 1982; Sommers, 1982; Zamel, 1985). Two critical points account for the occurrence of peer feedback.

First, peer feedback is accompanied by the change from the teacher-centered to the student-centered concept of language learning. In traditional English writing teaching, teachers generally adopt the behavior-based teaching method, that is, rote learning with teachers in the dominant position, but students do not gain enough training in their communicative ability. The development of teaching theories triggers a shift of focus from writing results to the writing process in contemporary writing teaching. In the early 1970 s, process-oriented writing teaching came into being (Chaudron, 1987: 673), which emphasizes the importance of students' participation and gives full play to the role of students in all aspects of writing, such as the collection of information, the formulation of writing plans, and the completion of writing (Graves, 1978: 15). The writing process is therefore seen as the focus of teaching, allowing students to learn to write dynamically (Keh, 1990: 294). In this process, peer feedback is regarded as a vital part (Zamel, 1985: 80), as through peer feedback students can obtain comments and suggestions from different channels to modify the writing, and at the same time enhance their reader awareness, so that students can be involved in writing activities more effectively and efficiently.

Second, under the guidance of the student-centered concept, peer feedback is the solution to the dichotomy between quality feedback and heavy workload, thus making up for the limitation of teacher feedback. In the traditional teacher-centered classroom, teacher feedback occupies an absolute authority in the writing process, and students can only passively accept it and modify the writing accordingly (Mendonca \& Johnson, 1994: 762). Admittedly, in the teaching of ESL or EFL writing, especially in many Asian countries, school education is mostly oriented to achievement. In other words, as the most widely used feedback method, teacher feedback is universally recognized by students and its authority is conducive to improving students' writing (cf. Ferris, 1995: 50; Ferris, 1997: 318; Yang et al., 2006: 199). However, from the perspective of student-centered teaching, there are obvious limitations in teacher feedback. One is in the cause of workload and lack of teaching resources. Due to a large number of students and a heavy burden on teachers, teachers often fail to evaluate each student carefully and detailedly. Some teachers even give rigid and unclear feedback, accounting for passive learning outcomes. As a result, a lot of time and energy were spent, but little was achieved (cf. Zamel, 1985: 79; Raimes, 1987: 440; Hyland, 1998: 280; Zhao, 2010:15). Second, the intervention of teachers makes students think little of the writing process, especially the drafting and revising process as they may rely too much on teachers. Also, the absolute authority of teachers will diminish students' confidence in using the language (Hyland, 2000: 34).

\subsubsection{Students' Attitude to Feedback}

There are conflicting views in the research on teacher feedback. Zamel (1985) believes that teachers' comments are often confusing and arbitrary, and do not convey the importance of revision to students. Truscott (1996) even suggests that in general, feedback on grammatical errors is ineffective. However, Ferris (1997) found that detailed and specific teacher feedback can effectively help students revise their articles, which is more obvious in Kepner's (1991) results that teacher feedback not only promotes the accuracy of expression but also improve student's writing skills. 
Studies on peer feedback have also presented a range of mixed results. Connor \& Asenavage (1994) found that only $5 \%$ of students' modifications to their writing were caused by peer feedback, but the figure rose to $14 \%$ in Paulus's (1999) experiment and as high as 53\% in the study of Mendonca \& Johnson (1994). The role of peer feedback in improving students' writing ability has been confirmed in many studies. Peer feedback can enhance students' awareness and sense of responsibility in active learning (Jacobs, 1989) and tap on students' potential to modify their writing spontaneously and effectively (Villamil \& Guerrero, 1998). Hedgcock \& Lefkowitz (1992) found that peer feedback can enable students to pay attention to the rhetorical structure of their own articles and cultivate the ability to modify basic language errors.

Existing studies mostly use questionnaires to gain a further and deeper understanding of students' attitudes towards different feedback methods. Many studies (e.g. Radecki \& Swales, 1988; Enginarlar, 1993; Ferris, 1995) show that students are generally in favor of teacher feedback. However, students' attitudes towards peer feedback vary from study to study. Mangelsdorf (1992) found that 55\% of respondents are in favor of using peer feedback; meanwhile, in Mendonca \& Johnson's (1994) research, students even consider peer feedback to be as important as teacher feedback. However, Nelson \& Murphy (1993) found that Chinese and Spanish students preferred teacher feedback, and ESL respondents of Zhang (1995) preferred teacher feedback. The conclusion of Tsui \& Ng's (2000) research is that students regard teacher feedback as being more authoritative, but they also acknowledge the value of peer feedback. While there are varied results, an approach has been proposed in between that combines various forms of feedback, especially teacher feedback and peer feedback (eg. Zhang, 1999; Jacobs et al., 1998; Mendonca \& Johnson, 1994).

Nelson \& Murphy (1993) believe that students' attitude towards peer feedback and its effectiveness depends on environmental factors, that is, the social/academic atmosphere in the classroom. The influence of Chinese teaching environmental factors on peer feedback is particularly noteworthy, for teachers have special authority in Chinese cultural values (Cortazzi \& Jin, 1996), which means that students may prefer teacher feedback to peer feedback. To understand whether peer feedback can be applied to the process of writing in an effective way, researchers need to explore how students implement peer feedback, how different their writing ability will be affected after peer feedback, and how they react to peer feedback. Therefore, Zamel (1987) pointed out that the "classroom-based" and "ethnographic" research method should be adopted simultaneously in order to better study the effect of peer feedback in college English writing teaching.

\subsection{Features of Peer Feedback}

\subsubsection{Effectiveness of Peer Feedback: A Practical Perspective}

Through a large number of empirical studies, researchers have tested the effectiveness of peer feedback in ESL writing teaching. Previous research found that peer feedback plays a positive and effective role in ESL writing (eg. Kroll \& Vann, 1981: 464; Topping, 1998; Berg, 1999; Tsui \& Ng, 2000; Cho \& Schunn, 2003; Saito \& Fujita, 2004; Schunn et al., 2016), mainly reflected in the following two aspects.

For one thing, peer feedback has a positive influence on the writing ability of second language learners. Keh (1990) found that learners can gain more knowledge about how to revise their writing and have a clearer understanding of high-quality writing by critically reading their peers' writing. In Berg's (1999) study of 46 English learners, he found that peer feedback makes a positive difference to the diversity of students' feedback types and writing quality. Meanwhile, peer feedback could cultivate students' critical thinking abilities, as illustrated by De Guerrero \& Villamil's (2000) observation that both sender and receiver of feedback can benefit from peer feedback.

For another, peer feedback exerts a positive impact on students' cognitive ability. Mendaonca \& Johnson (1994) believe that when students participate in peer feedback activities, they will play a more active role in learning to write, and at the same time, they can reconstruct the content of writing according to peer suggestions. In addition, in the process of giving feedback, students can grasp writing skills and use the corresponding techniques to provide feedback for their peers. For instance, Tsui \& Ng's (2000) interview of 27 students in a middle school in Hong Kong shows that peer feedback can help students enhance their audience awareness, recognize their strengths and weaknesses in writing more clearly, and promote students' initiative in effective writing.

\subsubsection{Feasibility of Peer Feedback: A Cognitive Perspective}

It is a cognitive problem that needs to be addressed via peer feedback whether there are obstacles from learners in the application of peer feedback in English writing teaching. Previous relevant studies have confirmed the existence of cognitive problems among learners. 
Studies have found that some learners consider teacher feedback to be authoritative and irreplaceable, and are subjectively unwilling to accept and use peer feedback (eg. Mendonca \& Johnson, 1994: 761; Zhang, 1995: 218; Carson \& Nelson, 1996: 13; Tsui \& Ng, 2000: 161; Yang et al., 2006: 191), especially in some Asian countries, where learners have long relied on teacher feedback in ESL or EFL writing teaching. Nelson \& Carson (1996) discovered that Chinese learners are reluctant to make public comments on their peers' compositions because of their fear of making mistakes and losing faces. Zhang (1995) surveyed 81 ESL learners in the United States and found that $76 \%$ of them regard teacher feedback as a better method than peer feedback. The same goes for the interviews of Yang et al. (2006), who found that from the perspective of students, teachers are more experienced, authoritative, and trustworthy. Some studies even found that most learners tend to use teacher feedback for writing modification (Connor \& Asenavage, 1994; Zhang, 1995; Tsui \& Ng, 2000).

Nevertheless, some studies found that learners lack experience and knowledge in using peer feedback because it is difficult for them to find mistakes and provide effective feedback. Even if mistakes are found, they do not know how to give high-quality feedback; therefore, the recipient of feedback will be suspicious of the ability of the partner and the accuracy of the feedback (cf. Mendonca \& Johnson, 1994: 747; Connor \& Asenavage, 1994: 270; Paulus, 1999: 267; Tsui \& Ng, 2000: 161; Hyland, 2000: 49).

These findings, on the one hand, reflect the cognitive view that learners are more inclined to accept teacher feedback than peer feedback; on the other hand, they also indicate their cognitive attitude towards the effectiveness of peer review. Plus, these findings also reveal teachers' anxiety about the application and effectiveness of peer feedback.

\subsection{Peer Feedback Training}

In order to overcome the possible cognitive obstacles caused by the application of peer feedback in writing teaching, researchers have carried out targeted research and found an effective method to make up for its shortcomings, i.e. peer feedback training. Studies have shown that peer feedback training can help learners make effective feedback, improve the quality of feedback, and help peers make effective modifications to their own writing (eg. Hedgcock \& Lefkowitz, 1992; Stanley, 1992; De Guerrero \& Villamil, 1994; Berg, 1999; Min, 2006; Loretto et al., 2016). In addition, learners' attitude towards peer feedback is influenced by their experiences and feelings in the process of peer feedback. When the influence of peer feedback on language development is perceived to be effective, learners will show a positive attitude towards peer feedback (Mendonca \& Johnson, 1994; Yang et al., 2006). Although there are some obstacles in the application of peer feedback, it has certain advantages over teacher feedback, which can reduce the workload of teachers, and better reflect the concept of student-centered cooperative learning. Therefore, peer feedback training has attracted attention and has begun to be used in ESL or EFL writing. In-depth research has been carried out on how to conduct peer feedback training, and a series of approaches and methods of peer feedback have been proposed so far (cf. Stanley, 1992; Berg, 1999; Min, 2006), which means research on peer feedback training and its application is of great significance.

In recent years, the methods of peer feedback training have been further developed. Lam (2010) divides the training into three stages: modeling, exploring, and consciousness-raising. In the modeling stage, teachers emphasize the modeling process of language and the expression of meaning in writing. In the exploring stage, learners apply what they have learned to revise the writing of others. In the consciousness-raising stage, learners are instructed to analyze the peer feedback they are given. Min (2006) made a more detailed study on the training method of peer feedback and found that the method of combining mastery classroom demonstration, i.e. showing learners the correct evaluation process and method, with teacher feedback to provide explanations has the most obvious effect on improving learners' peer feedback skills. More importantly, it has also been revealed that the application of peer feedback has a significant effect on ESL or EFL learners after training or mentoring during the writing process (cf. Paulus, 1999; Berg, 1999; Rahimi, 2013). In addition to improving the quality of feedback, training can promote the development of learners' writing skills, the establishment of their confidence in writing and giving feedback, and the use of meta-cognitive strategies (Min, 2005). Meanwhile, the writing purpose and reflection after peer feedback contribute to the quality of feedback (Zhang et al., 2017) as well. Learners can provide feedback for their peers cooperatively, read their writing from writers' angle, and make relevant evaluations. Meanwhile, learners are more willing to spend time and energy understanding the intentions of writers and help writers solve problems through cooperation (Min, 2008). The present study focuses on peer feedback training, with specific attention to peer feedback under teacher intervention, to explore and investigate its role in writing teaching. 


\section{Methodology}

\subsection{Participants}

Participants of this experiment are 90 freshmen in Business English major from a university in Southern China. They are randomly divided into three groups according to three different feedback methods, with 30 students in each group. Before this experiment, 90 students had received four basic writing training sessions. The average scores of the English university entrance examination of the three groups are 115.016, 115.029, and 114.985 respectively, which shows no significant difference in their English proficiency. At the very beginning, 90 students took an IELTS mock test (reading and writing), with an average score of 6.14, 6.22, and 6.12 respectively. As the test results show no conspicuous difference, it can be preliminarily confirmed that participants' English level and writing ability can be regarded as the same.

\subsection{Research Design}

The basic operating procedures of different groups of students are shown in Figure 1. To improve the operability of the experiment, the ordinary peer feedback group and the group under teacher intervention are further divided into 3 sub-groups respectively, to enable them to give and receive peer feedback.

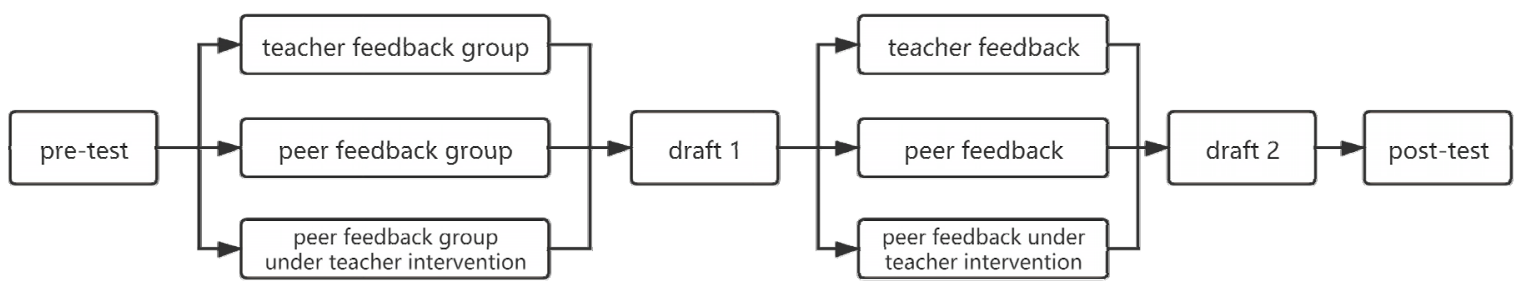

Figure 1. Research procedures of three feedback groups

Students in three groups are assigned the same writing task and complete the first draft of the writing task independently within a limited time in class. In the correcting stage, the teacher feedback group receives traditional teacher feedback; that is, the teacher corrects the article in a conventional manner and provides remarks in front of students. Then, students complete the second draft according to the teacher's comments and revising suggestions. The ordinary peer feedback group is divided into small groups respectively to share each article with different members, apply the evaluation standards (namely text content, text structure, language accuracy, and language proficiency), and give written or oral feedback. Through face-to-face communication, students make adjustments to their own writing according to the opinion of other members to form a writing idea, which is followed by the second draft. In the same way as the ordinary peer feedback group, students in the group under teacher intervention apply what they have learned in their notes. Under the guidance of systematic training and group discussion in advance from the teacher, students will review and revise their peers' writing. In the process of feedback, the teacher will make appropriate interventions accordingly, enabling the group members to complete the second draft. Finally, the three feedback groups submit the second draft together with the first draft to the teachers for review within a limited time.

Based on Lam's (2010) three stages of peer feedback training (modeling, exploring, and consciousness-awareness), this experiment will observe and compare students' different performances regarding the training process. During the experiment, in addition to feedback quality, the researcher conducts further interviews to evaluate the effects of peer feedback training on students. In the process of evaluation, teachers guide students to put forward feedback opinions for their peers as feedback givers and receivers from the cooperative perspective.

The experiment lasts for two months, and each student has completed two articles modified by one of the three feedback methods. As students need to be familiar with the feedback process, in the first round of writing activities, the teacher demonstrates how to provide feedback for the students with the peer feedback group and the intervention group and provide appropriate guidance for revision and communication so that students can be familiar with the experimental process of feedback. Therefore, this experiment selects the second article as the experimental case.

\subsection{Data Collection and Analysis}

In the experiment, SPSS is used for a comparative analysis of relevant data, and the feedback process is truly recorded and further analyzed through classroom observation and audio recording. 


\subsubsection{Observation and Recording}

The second feedback experiment is specially arranged with the assistance of recording equipment, so as to obtain the feedback information of the whole feedback process in different feedback groups. Then, the audio file containing the feedback information is converted into text for analysis. Finally, errors in the text are categorized in a list, including text content, text structure, language accuracy, language proficiency, and others. Due to the poor quality of some recordings, researchers further pick 53 recordings from the 6 feedback groups that are successfully converted from audios into valid texts, with 25 of them receiving peer feedback, and 28 of them receiving peer feedback under teacher intervention. For a better comparison, 25 texts of peer feedback and peer feedback under teacher intervention respectively are finally selected.

\subsubsection{Questionnaires and Interviews}

Questionnaires and interviews provide references for further data analysis. It is critical to determine the theoretical basis or source of some opinions in the revised draft as well as to understand the reasons why writers hold different attitudes towards different feedback opinions. The questionnaire mainly involves two aspects. One is how helpful students consider teacher feedback, peer feedback, and peer feedback under teacher intervention, and the other is which type of feedback method they prefer. In order to obtain the real opinions and attitudes on three feedback methods, this study conducts a face-to-face interview with each student with the questionnaire after the experiment. A total of 90 valid questionnaires and 90 valid texts extracted by recording conversion are collected, and 68 substantive feedback opinions are screened out for further evaluation.

\subsubsection{Further Interviews on Pre-Test and Post-Test}

Before and after the grouping experiment, a short writing test is set respectively, and students are then randomly selected for further interviews. The evaluation methods of the two tests follow the scoring requirements of the writing part of IELTS, including an overall evaluation and four specific evaluations. The overall evaluation is the teacher's overall impression of the article. Specific evaluations include text content, text structure, language accuracy, and language proficiency. The four teachers who grade the composition all have relevant experience in grading college English papers, and the score is the average from the four teachers. After the evaluation, further targeted interviews are conducted with students according to the results of pre-test and post-test.

\section{Findings and Discussions}

\subsection{Results of Composition Modifications}

Based on the comparison of 50 groups of text materials converted from audio files with the results of pre-test and post-test, we classify and comparatively analyze the feedback content of each writing task of each student in the peer feedback group and the intervention group, with specific results shown in Table 1.

Table 1. Results of feedback: types, frequency, and percentage

\begin{tabular}{lllll}
\hline \multirow{2}{*}{ Feedback contents } & \multicolumn{2}{l}{ Peer feedback group } & Peer feedback group under teacher intervention \\
\cline { 2 - 5 } & Frequency & Percentage & Frequency & Percentage \\
\hline Text content & 62 & $16.31 \%$ & 54 & $15.26 \%$ \\
Text structure & 36 & $9.47 \%$ & 62 & $17.51 \%$ \\
Language accuracy & 89 & $24.72 \%$ & 75 & $21.19 \%$ \\
Language proficiency & 174 & $48.33 \%$ & 155 & $43.79 \%$ \\
Others & 19 & $5.00 \%$ & 8 & $2.25 \%$ \\
Total & 380 & & 354 & \\
\hline
\end{tabular}

As can be seen from Table 1, the number of feedback opinions in the peer feedback group is more than that in the intervention group, and the distribution of specific feedback categories in the two groups is quite different. The peer feedback group focuses more on language accuracy, that is, grammar, spelling, and punctuation, etc., while the frequencies of the text structure and the text content are relatively low. The distribution of the intervention group is relatively directional, especially in terms of text structure and text content, obviously more than that of the peer feedback group. First of all, regarding the text structure, both groups put forward suggestions on the transition and cohesion of their peers' articles, and the intervention group also gives advice on on the overall layout and the coherence of the article. Besides, with regard to the text content, the intervention group provides more suggestions concerning the topics of their articles that deviate from what is anticipated, but feedback about the width and depth of the text content tends to be the same, while ideas of their articles from the 
peer feedback group present greater diversification. In addition, in terms of language accuracy (grammar, spelling, and punctuation), a total of 21 grammatical errors are highlighted in the feedback, with tense and spelling errors being the top two. Last but not least, there is no conspicuous difference in the language proficiency between these two groups, mainly focusing on the wrong collocation and choice of words.

Repeatedly listening to the recorded audio of feedback as well as analyzing text information leads to the finding that ideas of the peer feedback group are mainly affected by factors such as students' language ability, personal experience, and those in the intervention group are more or less limited due to the teacher's intervention, which triggers the convergence of opinions and reduces their creativity. The implementation process of peer feedback is a face-to-face communication one, in which students mainly use their own professional knowledge and language skills to brainstorm and come up with suitable feedback after discussion. It is also found that their feedback is limited by time, place, and their own understanding, so it is impossible for them to propose many modifications and extensions to the text structure and content as they are not confident of their understanding. Therefore, the peer feedback group usually carries out detailed and in-depth discussions on the vocabulary and grammar of the article, while feedback concerning the structure and content is not adequate. When students give peer feedback, their suggestions on the text structure and content are far less than those on grammar and vocabulary.

In the intervention group, due to regular communication with teachers for guidance, group members do not always focus merely on grammar and spelling mistakes but dare to offer feedback on the text structure as well as the topic, and the coherence with a further discussion and modification. In addition to language accuracy, particular attention is also paid to the text structure and language proficiency. However, due to the teacher's intervention, students rarely speak out freely in terms of the text content; instead, they tend to follow what the teacher has guided them to do. Therefore, the intervention group provides fewer suggestions on the text content, and students are less innovative than those in the peer feedback group. In the interview, several students said that in the group discussion, group members generally further their feedback around the suggestions given by teachers, which is similar to what usually occurs in the teacher feedback group where students tend to rely on the teacher, thus reducing their initiative in learning and revising as well. The main reason is that students generally believe that teacher feedback is more authoritative and comprehensive, so there is no need to waste time and energy modifying their articles. To a large extent, this over-reliance on teacher feedback reduces students' enthusiasm for independent learning. Compared with teacher feedback, peer feedback can skillfully reduce the occurrence of this situation, which proves that the combination of teacher feedback and peer feedback is effective (cf. Zhang, 1999; Jacobs et al., 1998). Peer feedback under teacher intervention can cultivate students' habits of spontaneous revision and autonomous learning, which can make up for the deficiency of teacher feedback in this aspect.

\subsection{Questionnaire and Interview Results}

\subsubsection{The Role of Feedback}

The questionnaire in this study includes five parts with certain questions. The first part is to answer 10 'yes' or 'no' questions in order to understand the students' overall evaluation of the three feedback methods. The other four parts mainly relate to specific evaluations of the feedback, including their acceptability of the methods, their writing anxiety, their interest in writing, and their writing levels, in the form of the 5 Likert scales (' 5 ' for 'totally agree'; ' 1 ' for 'totally disagree'), in order to understand the way students view these three kinds of feedback methods. The specific results of the questionnaire are shown in Table 2.

Table 2. Students' evaluation of three feedback methods to improve their English writing ability

\begin{tabular}{llll}
\hline Feedback & Teacher feedback & Peer feedback & Peer feedback under teacher intervention \\
\hline Acceptability & 3.82 & 3.16 & 3.52 \\
Anxiety & 1.96 & 3.41 & 2.88 \\
Interest & 2.76 & 3.54 & 3.58 \\
Ability & 3.16 & 3.18 & 3.31 \\
\hline
\end{tabular}

From Table 2, students in the experiment hold a positive attitude towards the three feedback methods. Students in the teacher feedback group have the highest overall acceptance, as high as 3.82. Through the interview, it can be interpreted that students are used to teacher feedback, and teacher feedback, as far as they are concerned, is more professional and credible than peer feedback, which also reflects that the teacher's guidance on student writing always occupies a significant role in the learning process. However, in terms of easing writing anxiety, the effect of teacher feedback (only 1.96) is significantly weaker than that of the other two feedback methods, 
indicating that students have certain worries about teacher feedback. During the interview, some students expressed their concern that the teacher's evaluations of their articles are too low, and they are even criticized to some extent. Moreover, they may be 'unable to write' when revising their articles due to their inadequate understanding of the teacher's comments. On the contrary, peer feedback (3.41) can alleviate writing anxiety with peer feedback under teacher intervention (2.88) in the middle, showing that these two feedback methods are more helpful to reduce students' psychological pressure in writing than teacher feedback, and help them better express their own opinions and understand others' feedback.

In the interview process, the results of enhancing writing interest and alleviating anxiety are similar; that is, the score of teacher feedback is lower than the other two feedback methods. In addition, in the teacher feedback group, the teacher only makes written evaluations and oral summaries for the whole group, so it is impossible to communicate with each student individually. This further indicates that peer feedback under teacher intervention, with its flexible and equal communication mode, can better exert students' independent initiative and learning enthusiasm, and enable students to participate actively in the discussion (cf. Jacobs, 1989; De Guerrero \& Villamil, 1998).

As for the improvement of writing ability, there is little difference between the three feedback methods, and their scores are all higher than 3.1, which reveals students' acknowledgement of different feedback methods, as well as the necessity and importance of feedback methods for improving writing ability. In the interview, 90 students all recognize the role of feedback in writing. Only by knowing others' opinions and suggestions on their articles can they know how to modify their articles and improve their writing skills effectively. The interview records also fully show that students' interest in writing is enhanced through peer feedback and peer feedback under teacher intervention. Overall, peer feedback methods can develop students' interest and enthusiasm in mastering English writing skills.

\subsubsection{Students' Evaluation of Feedback}

The first 10 questions of the questionnaire are mainly used to understand students' overall recognition of three feedback methods and their opinions on which feedback methods they prefer to adopt in their future writing. Some of the results are shown in Table 3.

Table 3. Students' overall recognition of three feedback methods \& their suggestions for improvement

\begin{tabular}{|c|c|c|c|c|c|c|c|}
\hline \multirow[t]{2}{*}{ Statements } & & \multicolumn{2}{|c|}{ Teacher feedback } & \multicolumn{2}{|c|}{ Peer feedback } & \multicolumn{2}{|c|}{$\begin{array}{l}\text { Peer feedback under } \\
\text { teacher intervention }\end{array}$} \\
\hline & & Yes & No & Yes & No & Yes & No \\
\hline \multirow{2}{*}{$\begin{array}{l}\text { I think this kind of feedback } \\
\text { works for me. }\end{array}$} & Frequency & 24 & 6 & 25 & 5 & 28 & 2 \\
\hline & Percentage & $80.00 \%$ & $20.00 \%$ & $83.33 \%$ & $16.67 \%$ & $93.33 \%$ & $6.67 \%$ \\
\hline \multirow{2}{*}{$\begin{array}{l}\text { I would like to continue } \\
\text { using this feedback. }\end{array}$} & Frequency & 16 & 14 & 21 & 9 & 24 & 6 \\
\hline & Percentage & $53.33 \%$ & $46.67 \%$ & $70.00 \%$ & $30.00 \%$ & $80.00 \%$ & $20.00 \%$ \\
\hline \multirow{2}{*}{$\begin{array}{l}\text { I would like to see this } \\
\text { feedback improved. }\end{array}$} & Frequency & 26 & 4 & 28 & 2 & 27 & 3 \\
\hline & Percentage & $86.67 \%$ & $13.33 \%$ & $93.33 \%$ & $6.67 \%$ & $90.00 \%$ & $10.00 \%$ \\
\hline \multirow{2}{*}{$\begin{array}{l}\text { I would like to try other } \\
\text { ways of getting feedback. }\end{array}$} & Frequency & 10 & 20 & 18 & 12 & 4 & 26 \\
\hline & Percentage & $33.33 \%$ & $66.67 \%$ & $60.00 \%$ & $40.00 \%$ & $13.33 \%$ & $86.67 \%$ \\
\hline
\end{tabular}

According to the data, a majority of students hold a positive attitude that the three feedback methods are helpful to improve their writing ability. There are, nevertheless, some negative comments from the interview, that several students do not understand peer feedback and how to improve their articles in the second draft. One student who participated in the peer feedback said that he could not reach the same opinion as other group members in the group discussion and was skeptical of peer feedback. Regarding whether to continue using the feedback method, the number of students in the intervention group who hold positive and negative attitudes is about the same, which indicates that the students have an indubitable trust and indisputable dependence on teacher feedback, but they also have both skeptical and curious attitude towards the new feedback method. This ambivalence is a typical feature of Chinese students and a typical reflection of the influence of the traditional education model (Cortazzi \& Jim, 1996). Students tend to believe in teachers' ability and experience in giving feedback and have long been convinced of the accuracy and authority of teacher feedback (Ysui \& Ng, 2000). On the contrary, students lack confidence in their own and their peers' language proficiency, and their passive learning attitude also makes them fear difficulties in new feedback methods. This situation fully explains the 
importance of peer feedback training as well as the necessity of teachers' guidance and instruction before the implementation of a new feedback method. After students are familiar with the feedback process and relevant skills, their fear will be greatly reduced in a way. Similar to what is shown in the peer feedback group, more than half of the students the intervention group agree to continue using the feedback method and most students hope to improve the method, indicating their willingness to see the feedback methods developed as there still exist some limitations.

Students tend to use different feedback methods. Most students hope to use other feedback methods on the basis of using the original feedback method, which is confirmed by the peer feedback group. This set of data fully reflects students' demands for different ways of giving feedback. During the interview, students in both the teacher feedback group and the peer feedback group express their willingness to flexibly use different feedback methods. On the one hand, they hope to get explicit evaluations from the teacher; on the other hand, equal communication among peers can not only enable them to enjoy a more relaxing and free space for creation but also enrich the content of writing and improve the quality of language. Furthermore, the intervention group has the above two advantages, and students have the highest overall evaluation and satisfaction of this feedback method. It can be seen that the flexible and comprehensive application of peer feedback under teacher intervention can highlight the advantages of each feedback method, and enable students to maintain a more enthusiastic learning attitude towards the improvement of their writing skills, so as to enhance the effectiveness of feedback.

\subsubsection{Further Discussions on Interview Results}

In order to ensure the validity of the test results, questions are designed in strict accordance with the requirements of the writing of IELTS according to the emphasis of the writing training during the experiment. The format of the essay is argumentative, the difficulty of the topic is the same, and the time limit is 40 minutes. The scores of the pre-test and the post-test are shown in Table 4 according to different items respectively. The study conducts interviews with students based on their previous and subsequent achievements.

Table 4. Comparison of pre-test and post-test results ( 25 points for the full mark of each item)

\begin{tabular}{llllllllll}
\hline \multirow{2}{*}{ Items } & \multicolumn{2}{l}{ Teacher feedback } & \multicolumn{3}{c}{ Peer feedback } & \multicolumn{4}{c}{$\begin{array}{l}\text { Peer feedback under teacher } \\
\text { intervention }\end{array}$} \\
\cline { 2 - 11 } & Pre-test & Post-test & Gap & Pre-test & Post-test & Gap & Pre-test & Post-test & Gap \\
\hline Text content & 20.112 & 21.222 & 1.110 & 20.113 & 21.503 & 1.390 & 20.109 & 21.518 & 1.409 \\
Text structure & 20.205 & 22.211 & 2.006 & 20.207 & 21.434 & 1.227 & 20.211 & 21.887 & 1.676 \\
Language accuracy & 18.522 & 18.989 & 0.467 & 18.525 & 19.872 & 1.347 & 18.519 & 19.968 & 1.449 \\
Language proficiency & 19.425 & 20.503 & 1.078 & 19.416 & 20.503 & 1.087 & 19.423 & 20.514 & 1.091 \\
\cline { 2 - 10 } Total & 78.264 & 82.925 & 4.661 & 78.261 & 83.312 & 5.051 & 78.262 & 83.887 & 5.625
\end{tabular}

Based on the overall results of students on different feedback methods, the writing level of the three groups has improved to a certain extent after the combination of writing feedback and writing training, which suggests that all three feedback methods can effectively improve students' writing skills and language abilities. But from the perspective of different items, each feedback method has different effects on the level of students' writing. In the teacher feedback group, students' improvement in the text structure is conspicuous, while in the peer feedback group, students make significant progress in terms of the text content and language accuracy, which reveals that students do not pay enough attention to basic language errors with regard to teacher feedback (cf. Truscott, 1996), while students will focus on spelling, grammar, and collocation in terms of peer feedback. Also, peer feedback can lead students to think about the text context. In the intervention group, the text structure, text content, language accuracy, and language proficiency have been obviously improved. Such a relatively balanced improvement proves the importance of combining different feedback methods, as different feedback methods have certain effects on different aspects of students' writing.

In order to compare the influence of three feedback methods on different parts of students' writing, the researcher conducts a one-way variance test on the post-test scores, and there is no significant difference between the three feedback methods in terms of total scores, indicating that the three feedback methods have similar effects on the improvement of students' writing skills, and the intervention group is slightly higher than the other two groups. However, in the comparison by classification, the influence of the three feedback methods on different aspects of students' writing is noticeably different. A cursory observation of data leads to the finding 
that in terms of the text content, the gap of the peer feedback group (1.409) is similar to that of the intervention group (1.390), while the gap of the teacher feedback group (1.110) is observably different from that of the other two feedback methods, suggesting that peer feedback has a great advantage in expanding and enriching the text content. It is proved from the interview that communication between peers can change the tension of giving feedback and play a critical role in the diversification of the text content. As for the text structure, the gap of the intervention group (1.676) is between that of the peer feedback group (1.227) and that of the teacher feedback group (2.006). It can be seen by comparing the data that teachers play an irreplaceable role in improving students' ability of the text structure. When it comes to language accuracy, the teacher feedback group shows no obvious improvement (0.467), while the peer feedback group and the intervention group present significant changes with similar trends. This is because small language units are easier for students to master than the text structure, proving that peer feedback can lead students to place emphasis on their basic language ability. As regards language proficiency, there is also no conspicuous difference in the three feedback methods, at 1.078, 1.087, and 1.091 respectively. A final comparison of the average scores reveals that the effect of teacher feedback on improving students' language proficiency is slightly less obvious than that of the other two feedback methods.

Results of the interview further support and interpret the statistics. First, objective and accurate macro-analysis provided by the teacher has a better guiding effect on the text structure of students' writing, and teachers' comments are more convincing to students than peer feedback. Additionally, peer feedback, based on its flexible and relaxing way of discussion, functions better than those from teacher feedback in the text content and language accuracy, and can also reduce writing anxiety and enhance writing interest. Last, with the intervention of teachers, peer feedback allows students to not only gain authoritative guidance from teachers but also have communication with peers without barriers, which also plays a positive role in enriching the content and modifying the language.

While students in the interview mention they do acquire more skills and methods in the intervention group, many students figure out that in practice, they have invested more time and energy in the training stage so that in the process of giving feedback, they have to grasp writing knowledge and use the corresponding skills to provide feedback for their peers. Most of them think that they mainly master the writing skills and techniques in the training stage, which is beyond the expectation that students should have made significant progress when giving and receiving feedback. Further research can be conducted to shed light on the influence of peer feedback and teacher intervention on students' learning psychology and cognitive ability on English writing teaching.

\section{Implications and Conclusions}

It is not only the focus of second language acquisition research but also one of the significant tasks for English teachers to improve the quality of English writing teaching. However, not only does it take teachers a lot of time and energy to correct students' articles, but what students learn is also very limited, because teacher feedback places students in a relatively passive state of acceptance. Given the authority of teacher feedback and the interactivity of peer feedback, this research adopts peer feedback training, that is, peer feedback under teacher intervention. This method is just as helpful to students as the way of relying entirely on teacher feedback, and peer feedback can also be carried out to replace part of teacher feedback. Therefore, peer feedback under teacher intervention can not only reduce teachers' burden but also improve students' writing initiative.

In the experiment, it is found that teacher feedback has a significant effect on enhancing students' writing awareness of the layout of the text, while peer feedback has a positive influence on expanding the content of the article and improving basic language skills as well as alleviating writing anxiety and improving writing interest, etc. Peer feedback under teacher intervention combines some characteristics of teacher feedback and peer feedback, which is more balanced on the whole and more effective in improving students' writing ability. While the steps, requirements, and methods of feedback are different, and students' familiarity with and acceptance of these methods varies as well, all of them can improve students' writing ability and language skills to a certain degree based on the present study. Only teacher feedback cannot guarantee that students can effectively improve all aspects of the article because of their difficulties in understanding and accepting teachers' opinions. Therefore, in writing teaching, full consideration should be given to the differences in students' cognitive ability and language skills, and the flexible application of various feedback methods targeted at different students.

The present study does show that peer feedback training, i.e. the combination of peer feedback and teacher feedback, is feasible and effective. Teachers should not only act as formidable authority graders and supervisors, but also as instructors, participants, organizers, coordinators, and readers who can communicate with students. During the implementation of teacher feedback, teachers should establish a friendly and equal cooperative 
relationship with students, and express the abstruse and general evaluation suggestions in a simpler and more specific way to ensure that students can understand and accept the feedback. As for peer feedback, through reasonable grouping and system training such as flexible, real-time monitoring, the teacher can guide students to participate actively in group discussions, attach importance to developing students' consciousness of readers, cooperation spirit, and creative ability, and solve various contradictions and conflicts in the process of feedback in time, so as to ensure that feedback can be orderly and efficiently implemented. Only by combining them flexibly and properly in writing teaching can their functions be fully realized, and the objectivity and rationality of writing evaluation. In the questionnaire and interview, most of the students express their willingness to use different feedback methods for writing evaluation, which proves the necessity of organically combining teacher feedback and peer feedback. Future research is suggested to further explore the combination of teacher feedback and peer feedback in different ways, such as peer feedback prior to teachers' feedback, to compare roles of different methods as well as different orders in the combination of feedback.

\section{Acknowledgments}

Sincere gratitude undoubtedly goes to my teaching assistant, Yi Chen, who assists in conducting this research with his contributions to the research design, interview arrangement, audio recording, and data analysis.

\section{References}

Berg, E. C. (1999). The effects of trained peer response on ESL students' revision types and writing quality. Journal of second language writing, 8(3), 215-241. https://doi.org/10.1016/S1060-3743(99)80115-5

Brannon, L., \& Knoblauch, C. H. (1982). On students' rights to their own texts: A model of teacher response. College composition and communication, 33(2), 157-166. https://doi.org/10.2307/357623

Carson, J. G., \& Nelson, G. L. (1996). Chinese students' perceptions of ESL peer response group interaction. Journal of second language writing, 5(1), 1-19. https://doi.org/10.1016/S1060-3743(96)90012-0

Chaudron, C. (1987). Analysis of Products and Instructional Approaches in Writing: Two Articles on the State of the Art: Introduction. Tesol Quarterly, 21(4), 673-675. https://doi.org/10.1002/j.1545-7249.1987.tb00947.x

Cho, K., \& Schunn, C. (2003). Validity and Reliability of Peer Assessments with a Missing Data Estimation Technique. In D. Lassner \& C. McNaught (Eds.), Proceedings of ED-MEDIA 2003--World Conference on Educational Multimedia, Hypermedia \& Telecommunications (pp. 1511-1514). Honolulu, Hawaii, USA: Association for the Advancement of Computing in Education (AACE).

Connor, U., \& Asenavage, K. (1994). Peer response groups in ESL writing classes: How much impact on revision? Journal of second language writing, 3(3), 257-276. https://doi.org/10.1016/1060-3743(94)90019-1

Cortazzi, M., \& Jin, L. (1996). Cultures of Learning: Language Classrooms in China. In H. Coleman (Ed.), Society and the Language Classroom (pp. 169-206). Cambridge, England: Cambridge University Press.

De Guerrero, M. C., \& Villamil, O. S. (2000). Activating the ZPD: Mutual scaffolding in L2 peer revision. The Modern Language Journal, 84(1), 51-68. https://doi.org/10.1111/0026-7902.00052

Dheram, P. K. (1995). Feedback as a two-bullock cart: A case study of teaching writing. ELT Journal, 49(2), 160-168. https://doi.org/10.1093/elt/49.2.160

Enginarlar, H. (1993). Student response to teacher feedback in EFL writing. System, 21(2), 193-204. https://doi.org/10.1016/0346-251X(93)90041-E

Ferris, D. R. (1995). Student reactions to teacher response in multiple-draft composition classrooms. TESOL quarterly, 29(1), 33-53. https://doi.org/10.2307/3587804

Ferris, D. R., Pezone, S., Tade, C. R., \& Tinti, S. (1997). Teacher commentary on student writing: Descriptions \& implications. Journal of second language writing, 6(2), 155-182. https://doi.org/10.1016/S1060-3743(97)90032-1

Graves, D. H. (1978). Balance the Basics: Let Them Write. New York: Ford Fountain.

Hedgcock, J., \& Lefkowitz, N. (1992). Collaborative oral/aural revision in foreign language writing instruction. Journal of second language writing, 1(3), 255-276. https://doi.org/10.1016/1060-3743(92)90006-B

Hyland, K. (1990). Providing productive feedback. ELT Journal, $44(4)$, 279-285. https://doi.org/10.1093/elt/44.4.279 
Hyland, F. (1998). The impact of teacher written feedback on individual writers. Journal of second language writing, 7(3), 255-286. https://doi.org/10.1016/S1060-3743(98)90017-0

Hyland, F. (2000). ESL writers and feedback: Giving more autonomy to students. Language teaching research, 4(1), 33-54. https://doi.org/10.1177/136216880000400103

Jacobs, G. M. (1989). Miscorrection in peer feedback in writing class. RELC Journal, 20(1), 68-76. https://doi.org/10.1177/003368828902000105

Jacobs, G. M., Curtis, A., Braine, G., \& Huang, S. Y. (1998). Feedback on student writing: Taking the middle path. Journal of second language writing, 7(3), 307-317. https://doi.org/10.1016/S1060-3743(98)90019-4

Keh, C. L. (1990). Feedback in the writing process: A model and methods for implementation. ELT Journal, 44(4), 294-304. https://doi.org/10.1093/elt/44.4.294

Kepner, C. G. (1991). An experiment in the relationship of types of written feedback to the development of second-language writing skills. The modern language journal, 75(3), 305-313. https://doi.org/10.2307/328724

Kroll, B. M., \& Vann, R. J. (1981). Exploring Speaking-Writing Relationships: Connections and Contrasts. Urbana, IL: National Council of Teachers of English.

Lam, R. (2010). A peer review training workshop: Coaching students to give and evaluate peer feedback. TESL Canada Journal, 27(2), 114. https://doi.org/10.18806/tesl.v27i2.1052

Lee, I. (1998). Supporting greater autonomy in language learning. ELT Journal, 52(4), 282-290. https://doi.org/10.1093/elt/52.4.282

Liu, J., \& Hansen, J. G. (2002). Peer Response in Second Language Writing Classroom. Ann Arbor: University of Michigan Press. https://doi.org/10.3998/mpub.8952

Loretto, A., DeMartino, S., \& Godley, A. (2016). Secondary students' perceptions of peer review of writing. Research in the Teaching of English, 134-161. Retrieved from https://www.jstor.org/stable/24889912

Mangelsdorf, K. (1992). Peer reviews in the ESL composition classroom: What do the students think? ELT journal, 46(3), 274-284. https://doi.org/10.1093/elt/46.3.274

Mendonca, C. O., \& Johnson, K. E. (1994). Peer review negotiations: Revision activities in ESL writing instruction. TESOL quarterly, 28(4), 745-769. https://doi.org/10.2307/3587558

Min, H. T. (2005). Training students to become successful peer reviewers. System, 33(2), 293-308. https://doi.org/10.1016/j.system.2004.11.003

Min, H. T. (2006). The effects of trained peer review on EFL students' revision types and writing quality. Journal of second language writing, 15(2), 118-141. https://doi.org/10.1016/j.jslw.2006.01.003

Min, H. T. (2008). Reviewer stances and writer perceptions in EFL peer review training. English for specific purposes, 27(3), 285-305. https://doi.org/10.1016/j.esp.2008.02.002

Nelson, G. L., \& Murphy, J. M. (1993). Peer response groups: Do L2 writers use peer comments in revising their drafts? TESOL quarterly, 27(1), 135-141. https://doi.org/10.2307/3586965

Paulus, T. M. (1999). The effect of peer and teacher feedback on student writing. Journal of second language writing, 8(3), 265-289. https://doi.org/10.1016/S1060-3743(99)80117-9

Radecki, P. M., \& Swales, J. M. (1988). ESL student reaction to written comments on their written work. System, 16(3), 355-365. https://doi.org/10.1016/0346-251X(88)90078-4

Rahimi, M. (2013). Is training student reviewers worth its while? A study of how training influences the quality of students' feedback and writing. Language teaching research, 17(1), 67-89. https://doi.org/10.1177/1362168812459151

Raimes, A. (1987). Language proficiency, writing ability, and composing strategies: A study of ESL college student writers. Language learning, 37(3), 439-468. https://doi.org/10.1111/j.1467-1770.1987.tb00579.x

Saito, H., \& Fujita, T. (2004). Characteristics and user acceptance of peer rating in EFL writing classrooms. Language Teaching Research, 8(1), 31-54. https://doi.org/10.1191/1362168804lr133oa 
Schunn, C., Godley, A., \& DeMartino, S. (2016). The reliability and validity of peer review of writing in high school AP English classes. Journal of Adolescent \& Adult Literacy, 60(1), 13-23. https://doi.org/10.1002/jaal.525

Sommers, N. (1982). Responding to student writing. College composition and communication, 33(2), 148-156. https://doi.org/10.2307/357622

Stanley, J. (1992). Coaching student writers to be effective peer evaluators. Journal of second language writing, l(3), 217-233. https://doi.org/10.1016/1060-3743(92)90004-9

Topping, K. (1998). Peer assessment between students in colleges and universities. Review of educational Research, 68(3), 249-276. https://doi.org/10.3102/00346543068003249

Truscott, J. (1996). The case against grammar correction in L2 writing classes. Language learning, 46(2), 327-369. https://doi.org/10.1111/j.1467-1770.1996.tb01238.x

Tsui, A. B., \& Ng, M. (2000). Do secondary L2 writers benefit from peer comments? Journal of second language writing, 9(2), 147-170. https://doi.org/10.1016/S1060-3743(00)00022-9

Villamil, O. S., \& Guerrero, M. C. D. (1998). Assessing the impact of peer revision on L2 writing. Applied linguistics, 19(4), 491-514. https://doi.org/10.1093/applin/19.4.491

Yang, M., Badger, R., \& Yu, Z. (2006). A comparative study of peer and teacher feedback in a Chinese EFL writing class. Journal of second language writing, 15(3), 179-200. https://doi.org/10.1016/j.jslw.2006.09.004

Zamel, V. (1985). Responding to student writing. TESOL quarterly, 19(1), 79-101. https://doi.org/10.2307/3586773

Zamel, V. (1987). Recent research on writing pedagogy. TESOL quarterly, 21(4), 697-715. https://doi.org/10.2307/3586990

Zhang, F., Schunn, C. D., \& Baikadi, A. (2017). Charting the routes to revision: An interplay of writing goals, peer comments, and self-reflections from peer reviews. Instructional Science, 45(5), 679-707. https://doi.org/10.1007/s11251-017-9420-6

Zhang, S. (1995). Reexamining the affective advantages of peer feedback in the ESL writing class. Journal of Second Language Writing, 4(3), 209-222. https://doi.org/10.1016/1060-3743(95)90010-1

Zhang, S. (1999). Thoughts on some recent evidence concerning the affective advantage of peer feedback. Journal of Second Language Writing, 8(3), 321-326. https://doi.org/10.1016/S1060-3743(99)80119-2

Zhao, H. (2010). Investigating learners' use and understanding of peer and teacher feedback on writing: A comparative study in a Chinese English writing classroom. Assessing Writing, 15(1), 3-17. https://doi.org/10.1016/j.asw.2010.01.002

Zhu, W. (1995). Effects of Training for Peer Response on Students' Comments and Interaction. Written Communication, 12(4), 492-528. https://doi.org/10.1177/0741088395012004004

\section{Copyrights}

Copyright for this article is retained by the author(s), with first publication rights granted to the journal.

This is an open-access article distributed under the terms and conditions of the Creative Commons Attribution license (http://creativecommons.org/licenses/by/4.0/). 